\title{
Three Dimensional Seepage Analyses in Mollasadra Dam after Its Impoundments
}

\section{GHOLAM REZA RAKHSHANDEHROO' ${ }^{1}$ MOHAMMAD VAGHEFI ${ }^{2 *}$; ALI REZA HEKMAT ZADEH ${ }^{3}$}

\author{
${ }^{1}$ Civil Engineering Department, Engineering Faculty, Shiraz University, Iran, Shiraz. \\ ${ }^{2 *}$ Civil Engineering Department, Engineering Faculty, Persian Gulf University, Iran, Bushehr \\ ${ }^{3}$ Civil Engineering Department, Engineering Faculty,Shiraz University, Iran,Shiraz.
}

\begin{abstract}
Mollasadra dam is an earth fill dam with a clayey core and a height of $72 \mathrm{~m}$ from river bed, constructed on Kor River. pore water pressure in the dam was investigated following its construction and first and second impoundments. The dam was modeled by a finite element mesh. After the first and second dam impoundments, the overall trend in monitored pore water pressure was well modeled by the transient analysis. The result showed the six month time period between impoundments was long enough for the pore water pressure to reach equilibrium everywhere throughout the core, except where considerable initial constructioninduced pore water pressure was observed. High values of construction-induced pore water pressure at elevation $2050 \mathrm{~m}$ did not dissipate completely during the 6 month period of almost constant reservoir level (el. $2098.3 \mathrm{~m}$ ) and the pore pressures were still at the transient state throughout the core. Therefore, it was concluded that pore pressures in the core of earth fill dams may not achieve steady state conditions even several months after the dam construction and impoundments. @JASEM
\end{abstract}

Key words: Pore Water Pressure, Transient Analysis, Seepage

Construction of a dam plays a vital role in development of a region. Therefore, confidence on safety of earth dams during their construction, impoundment, and operation is one of the most important reasons for monitoring pore water pressure within the dam. Other reasons, which are important to researchers, are better understanding of seepage flow patterns through the dam, dam's deformation, and strength (Kutzner, 1997).

Some problems like seepage failure and slope stability are significantly affected by pore water pressure in embankment dams. Usually the designers utilize a two dimensional seepage analysis in a typical cross section of embankment dam (Serafi, and Santos, 1985). However, this simplification may be deceptive in V shaped valleys (Jafarzadeh, and Shafipour, 2003). Also this analysis has problem in a case where high variation of material property exists across the valley (Jafarzadeh, and Shafipour, 2003). Comparison of pore water pressure in various sections of an embankment dam is another capability of 3D seepage analysis, something which cannot be considered in a 2D analysis (Guangxin and Jinhong, 2003).

Piezometers are one of the most common devices utilized for monitoring pore water pressure in earth dams (U.S. Army Corps of Engineering, 1995). Their readings reflect how different elements of a dam such as core, and embankment operate. Various types of piezometers are installed in an embankment dam; standpipe and vibrating wire being the most famous ones. Usually, piezometers diversity makes it possible to compensate their drawbacks (Dunnicliff, and Green, 2001).

In this article, monitored pore water pressure heads during 15 month of first and second impoundments were investigated on Molasadra dam. Three dimensional seepage flows were modeled by finite element method at both transient and steady sate according to appropriate initial and boundary conditions. Seep3D software, provided by GEOSLOPE International Ltd, was used to perform the analysis. Modeled pore water pressure heads were compared to monitored heads, and the response of heads in core due to construction and impoundments were discussed. In addition, the effects of change in certain input parameters, such as conductivity as a function of pore water pressure, on the results were investigated.

\section{MATERIALS AND METHODS Characteristics of The Dam}

Molasadra dam has been constructed on "Tange Boragh" waterfall at the upstream reaches of Kor River (Sefid River) in Bakhtegan basin, Fars province, Iran. Its distance to the capital of Fars Province, Shiraz, is about $200 \mathrm{Km}$. The dam is an earth fill dam with a central clayey core. The core material classified as GC according to unified classification system. This dam is a reservoir dam with total volume of $440 \mathrm{Mm}^{3}$ at its normal pool level and $2.5 \mathrm{Mm}^{3}$ earth fill volume. The dam has a maximum height of $72 \mathrm{~m}$ from river bed and $77 \mathrm{~m}$ from core foundation. It has a well-constructed grout curtain with an average depth of $60 \mathrm{~m}$ underneath its foundation. The crest is $650 \mathrm{~m}$ long and $10 \mathrm{~m}$ wide at the elevation of $2122 \mathrm{~m}$ from the mean sea level. The core has a side slope of $0.35 \mathrm{H}$ : $1 \mathrm{~V}$ with top width of $6 \mathrm{~m}$. The dam is constructed on a wide valley shown in Figure 1. For the sake of brevity only data from certain piezometers, which represent the hydraulic behavior of the dam, are presented in this paper. These piezometers are shown with black circles on Figure 1.

Various types of instruments such as electrical and stand pipe piezometers, electrical pressure cells, inclinometers, observation wells, settlement gauges and accelerometers have been installed in 6 monitoring sections along the dam. 
Three dimentional seepage

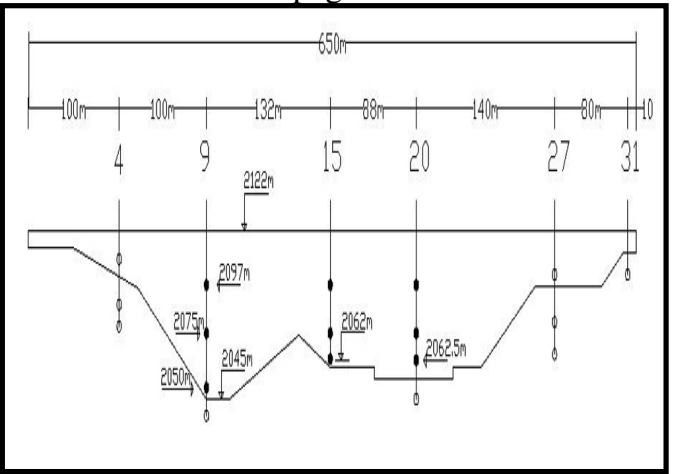

Fig 1: Monitoring sections and location of piezometers installed at the cross section of Mollasadra dam valley

\section{RESULTS AND DISCUSSION}

Results of Monitored Pore Water Pressure: Figure 2 shows a history of electrical piezometers readings, reservoir level, and construction height. As shown, the reservoir level remained almost constant for 6 months between the first and second dam impoundments. The trend in heads read by piezometers during first $\sim 300$ days is very interesting; it shows some heads higher than reservoir level with no sign of being affected by the reservoir level. Instead, the trend shows that pore water pressure was affected (increased) by (increasing) dam construction height. It was postulated that a high pore water pressure was actually induced in the core during the dam construction which dissipated when the construction stalled for a later 8 month period.

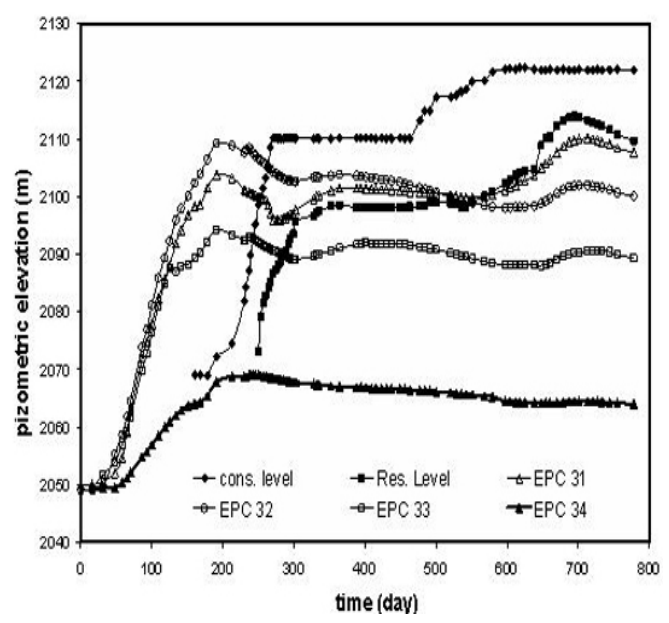

Fig 2: Monitored heads, reservoir level, and construction height at elevation 2050 (sec. 9)

Dissipation of excess pore water pressure occurred during the first dam impoundment. However, by the conclusion of the impoundment period, piezometers started to feel the impoundment and responded to it almost in the order of their proximity to the upstream face of the core. EPC 31, 32, and 33 showed a slight increase in their heads while EPC 34 did not appear to be affected by the impoundment. Apparently, by the end of impoundment, piezometers were still under the influence of pore water pressure heads induced by construction with EPC 31 and 32 showing heads higher than the reservoir level.

The dissipation of pore water pressure continued during the period between the first and second impoundments while the reservoir level was almost constant at elevation $2098.2 \mathrm{~m}$. However, the dissipation rate was much lower than the initial rate. By the end of this period all piezometers showed heads lower than the reservoir level. It suggests that 12 months after the first stage of construction, the construction-induced pore water pressures had dissipated completely. This time almost matched the commencement of the second impoundment.

Calibration: Four in-situ hydraulic conductivity tests were performed during the core construction. Based on these tests, values of hydraulic conductivity for the core varied between $10^{-7} \mathrm{~m} / \mathrm{sec}$ to $10^{-10} \mathrm{~m} / \mathrm{sec}$. To find a unique value for the conductivity, calibration was performed utilizing the monitored data. Several electrical piezometers from different sections and elevations were selected for calibration.

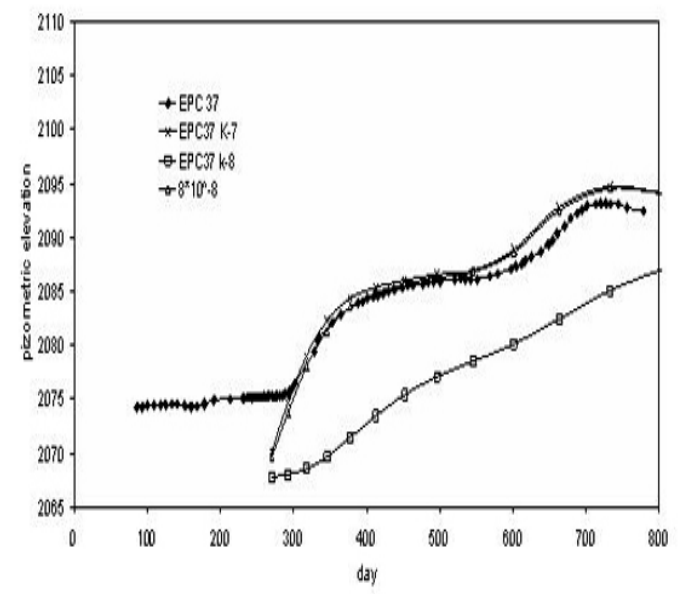

Fig 3: monitored and calculated heads for different values of saturated hydraulic conductivity at EPC37

Figures 3 and 4 display monitored and calculated heads for different values of saturated hydraulic conductivity at EPC16 and EPC37 as typical data. As seen, a hydraulic conductivity of $8 * 10^{-8} \mathrm{~m} / \mathrm{sec}$ gives the best fit for the monitored data.

Hydraulic conductivity variation as a function of pressure was not available for the core materials. Therefore, two different functions, as shown on figure 5, were considered. Modeling Results: For the sake of brevity, in the remainder of this article, monitored and calculated heads at different elevations of the core are compared at three interesting times. These times are shown as 1,2, and 3 on Figure 6; the reservoir level and calculated heads at EPC37 as a typical time series. 


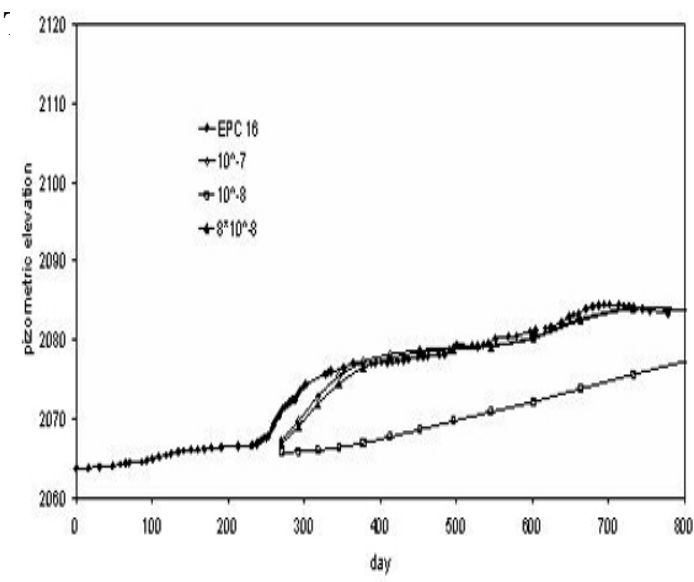

Fig 4: monitored and calculated heads for different values of saturated hydraulic conductivity at EPC16

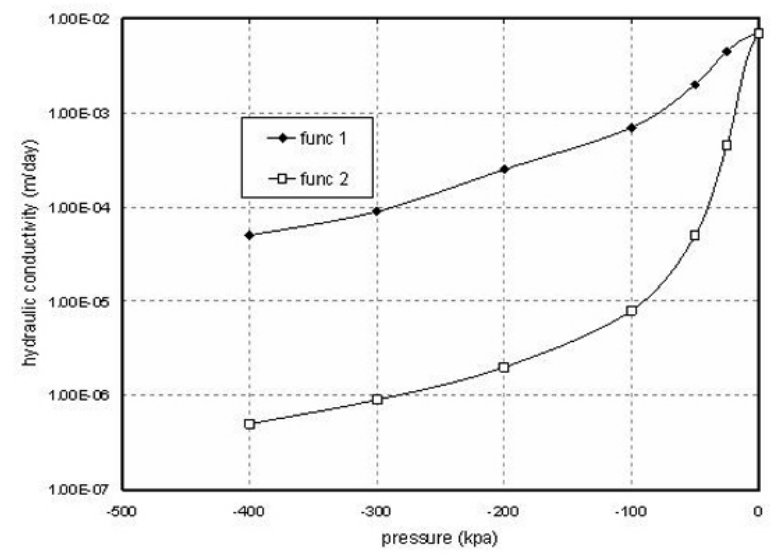

Fig 5: different conductivity versus pressure functions used for unsaturated zone

Times 1 and 3 are right after first and second impoundments, respectively. Time 2 is $\sim 6$ months after the first impoundment and right before the second one. The importance of these three times is obvious on figure 12 , as they are the times when maximum changes in observed and calculated heads occur.

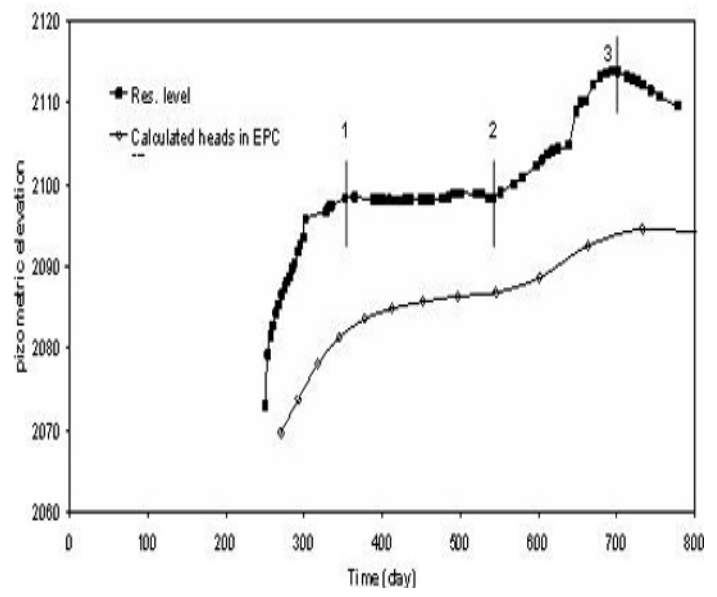

Fig 6: Reservoir level and calculated heads as functions of time at EPC 37
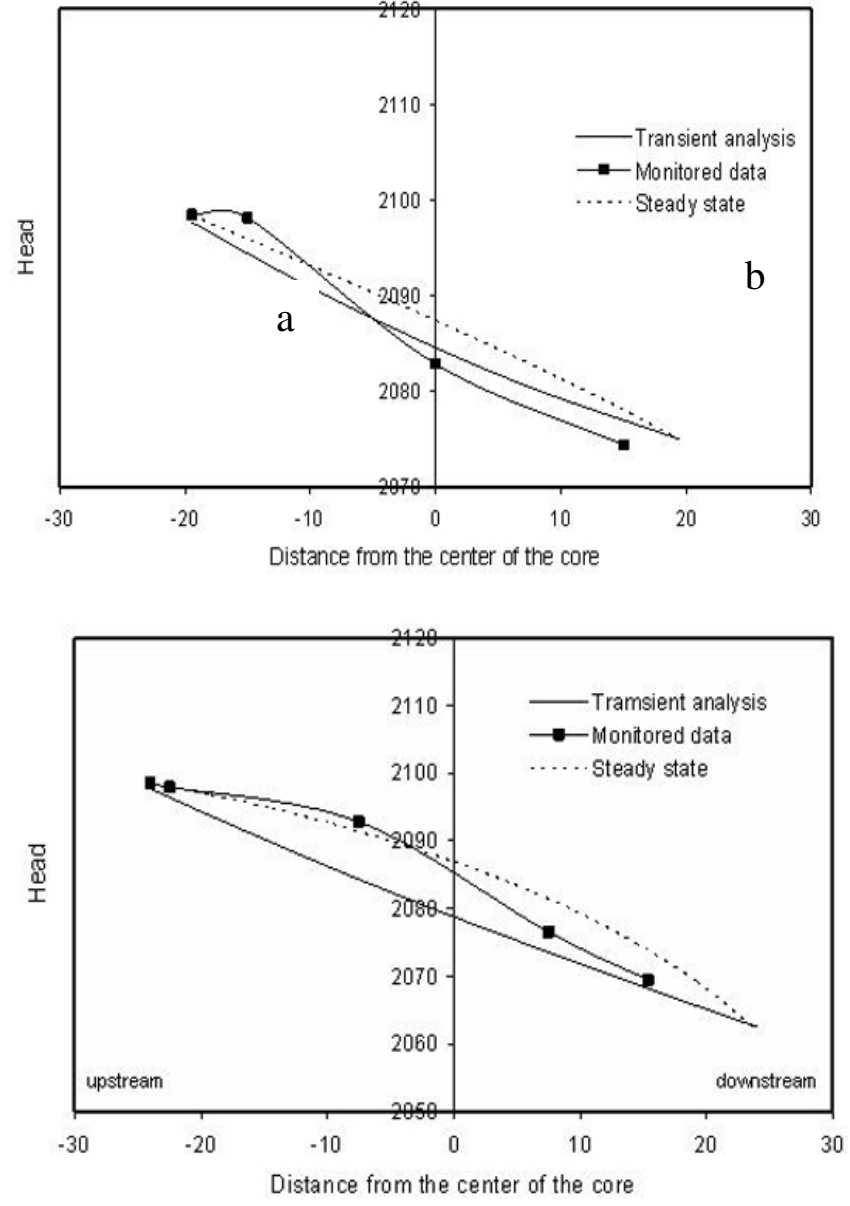

Fig 7: Heads at instant 1 versus horizontal location at elevations (a) 2062.5 (sec. 20) (b) 2075 (sec. 9)

Monitored heads as well as calculated heads (by steady and transient analyses) at instant 1 are shown on Figure 7a at elevation $2062.5 \mathrm{~m}$ in section 20. As shown on the figure, the steady and transient analyses have yielded different results. Furthermore, the monitored head are closer to the steady state results at the upstream face of the core and closer to the transient results at the downstream face. Similar results were obtained at elevation $2062 \mathrm{~m}$ in section 15. Heads at a different elevation $(2075 \mathrm{~m})$ at instant 1 are shown on Figure $7 \mathrm{~b}$. The general trend in monitored heads is again very similar to the trend al elevation $2062.5 \mathrm{~m}$. However, at this elevation monitored data seem to be better simulated by transient analysis. It is postulated that the overall pore water pressure at instant 1 was transient, especially at downstream face of the core.

Figures 8 show heads at instant 2 at elevations 2062.5 $\mathrm{m}$ and $2075 \mathrm{~m}$ in sections 9 and 20, respectively. As seen, the steady and transient analyses have yielded somewhat similar results.

Apparently, the six month time period between instants 1 and 2 has been long enough for the pore water pressure at these elevations to reach equilibrium. These results parallel the monitored heads shown on figures 4 and 5 where no considerable initial construction-induced pore water 
Three dimentional seepage pressure is observed at elevations $2062.5 \mathrm{~m}$ and 2075 $\mathrm{m}$.
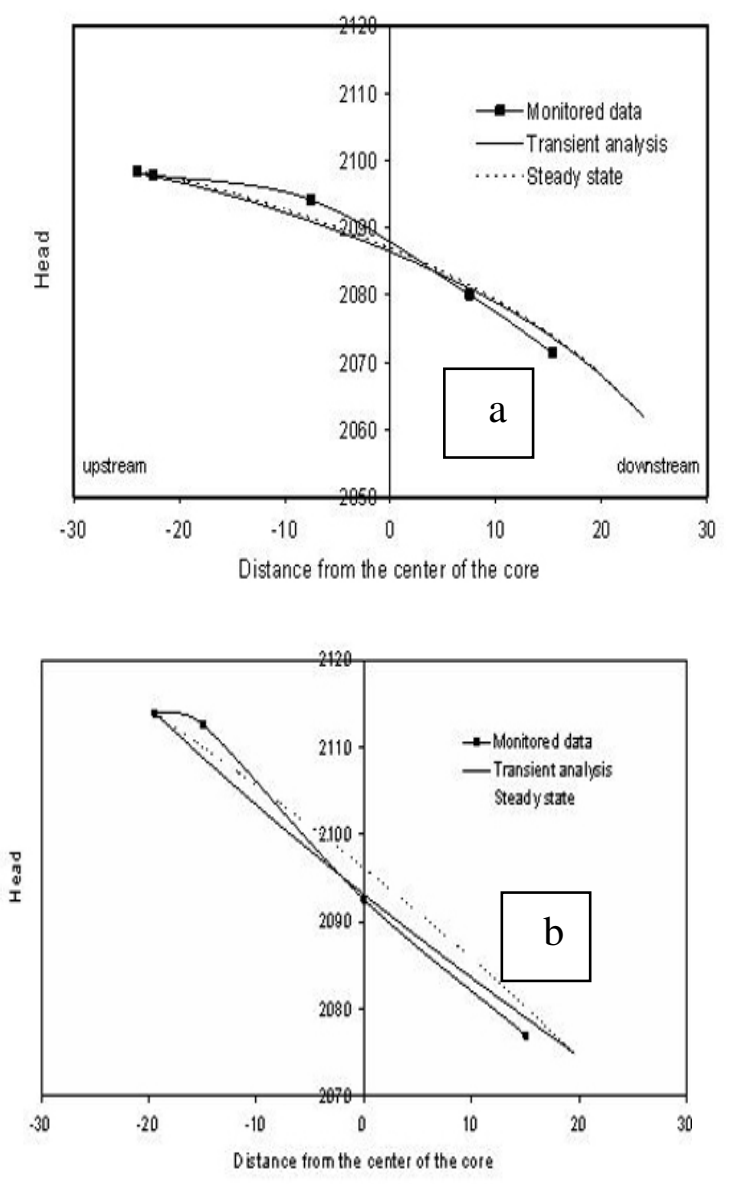

Fig 8: Heads at instant 2 versus horizontal location at elevation (a) 2062.5 (sec. 20) (b) 2075 (sec. 9)

Figures 9 display heads for elevations $2062.5 \mathrm{~m}$ and $2075 \mathrm{~m}$ at instant 3. Calculated heads for transient and steady state analyses are also shown on these figures. It is worth noting that during the $\sim 5$ month period between instants 2 and 3, the second dam impoundment occurred and reservoir level increased from elevation $2098.4 \mathrm{~m}$ to $2113.9 \mathrm{~m}$. As expected, the steady and transient analyses have yielded different results. Furthermore, similar to instant 1, the monitored heads are closer to the steady state results at the upstream face of the core and closer to the transient results at the downstream face. The fact that pore water pressures at the downstream parts of the core require long time to reach steady state conditions after the first and second impoundments reflects the proper hydraulic behavior of the core.

Piezometers installed at elevation $2097 \mathrm{~m}$ were typically positioned above the phreatic line in the core prior to instant 2 . Therefore, no conclusion is drawn from piezometers reading at this time.

Figure 10 shows heads at instant 3 at elevation 2097 m. As shown, the transient and steady state heads coincide with each other. As shown, monitored heads follow their trend with negligible difference. Therefore, it was concluded that the seepage flow was at steady state conditions at this level. A comparison of Figures reveals that there is a trend in the difference between transient and steady heads at different elevations; the higher the elevation, the smaller the difference. It is postulated that the thinner cross section at higher elevations required shorter times for heads to reach steady state conditions following the second impoundment.
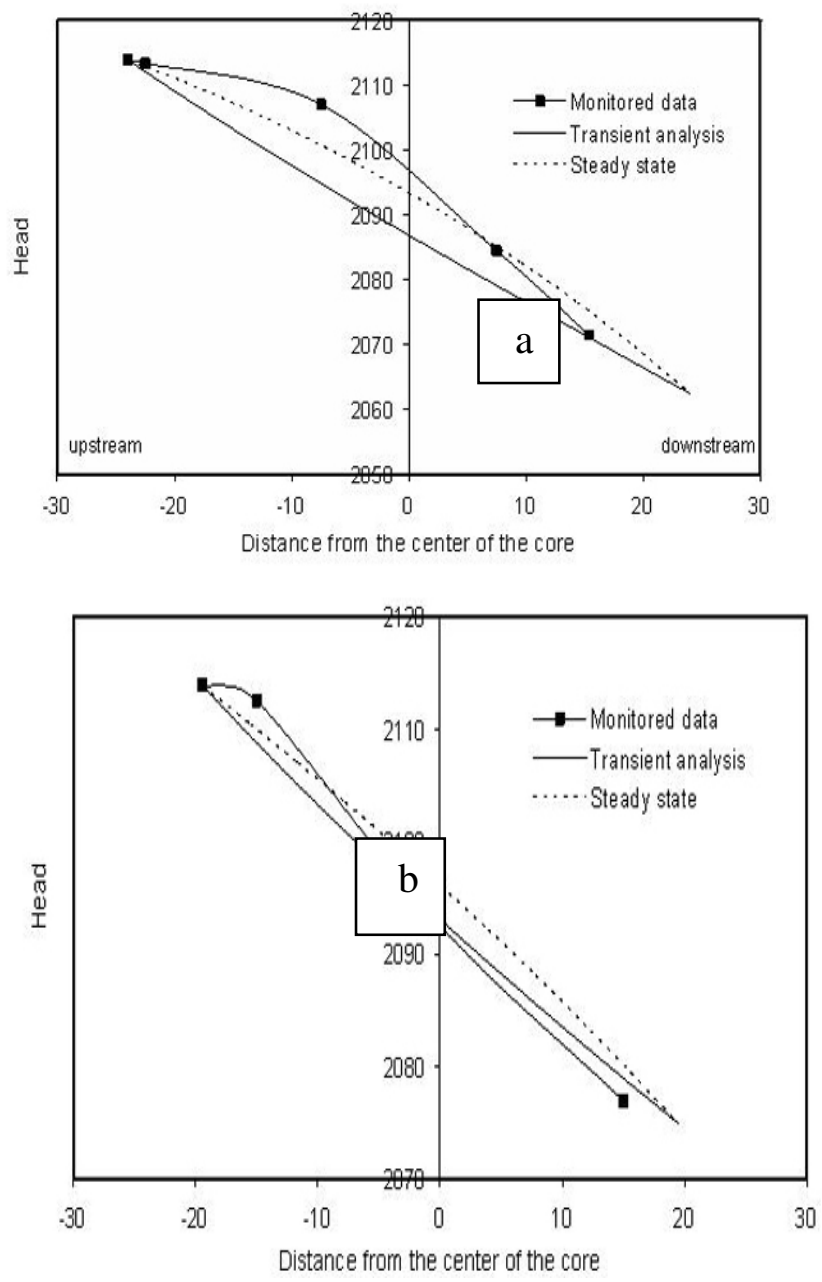

Fig 9: Heads at instant 3 versus horizontal location at elevation (a) 2062.5 (sec. 20) (b) 2075 (sec. 9)

Figures 11, 12, and 13 show monitored heads and heads at steady state and transient conditions at elevation $2050 \mathrm{~m}$ (the lowest instrumented elevation in the core) at instants 1,2 , and 3 , respectively. As shown on figures 11 , monitored head at this elevation were very close to transient conditions at instant 1 throughout the core. It contrasted the monitored heads behavior at the upstream face of the core in higher elevations, where they had reached steady state conditions. It is postulated that the high values of construction-induced pore water pressure (shown on Fig. 2) was retained at this elevation even following the first impoundment. Similar trend was observed at instant 2 (Figure 12) where monitored heads were still at transient conditions even $\sim 6$ months after the first impoundment. 
Three dimentional seepage

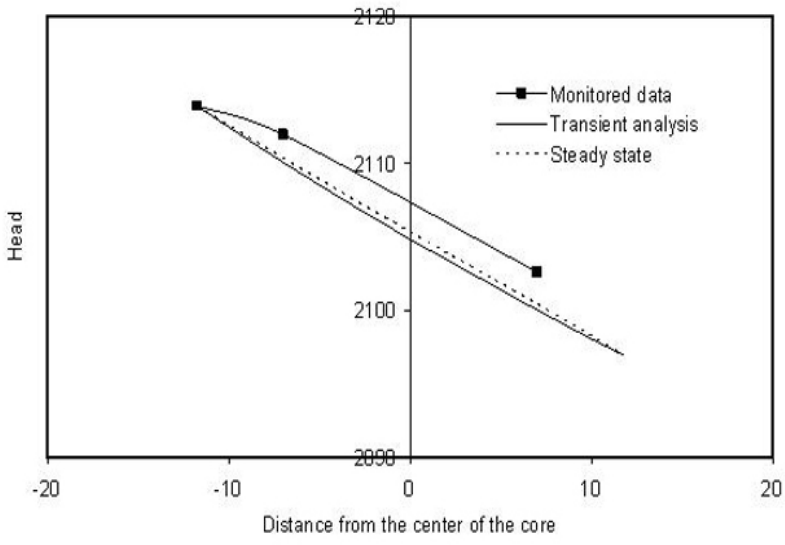

Fig 10: Heads at instant 3 at elevation 2097 (sec. 15) versus horizontal location

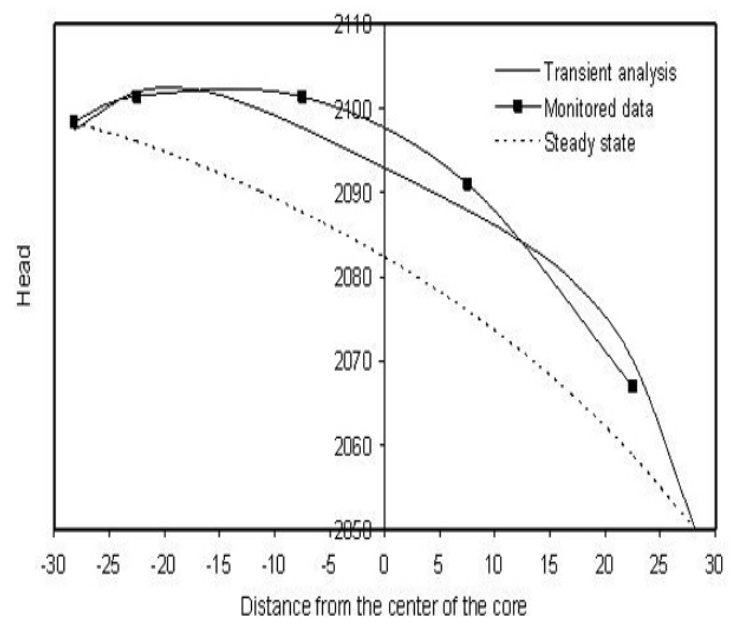

Fig 11: Heads at instant 1 at elevation 2050 (sec. 9) versus horizontal location

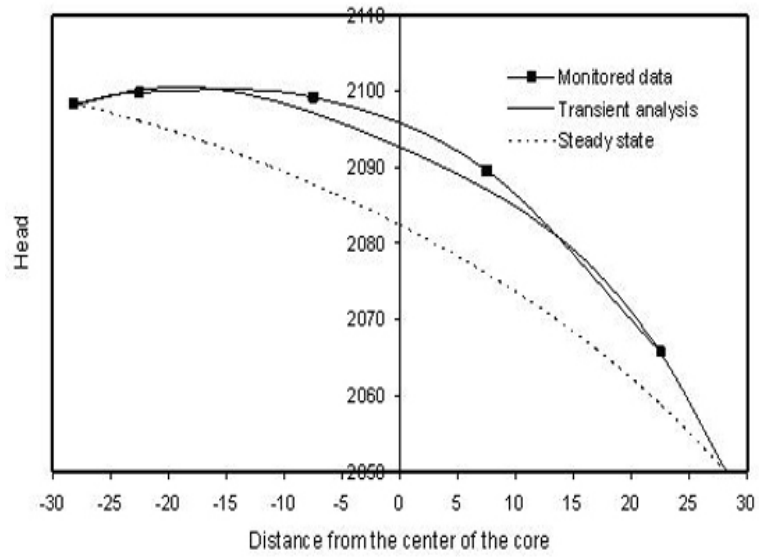

Fig 12: Heads at instant 2 at elevation 2050 (sec. 9) versus horizontal location

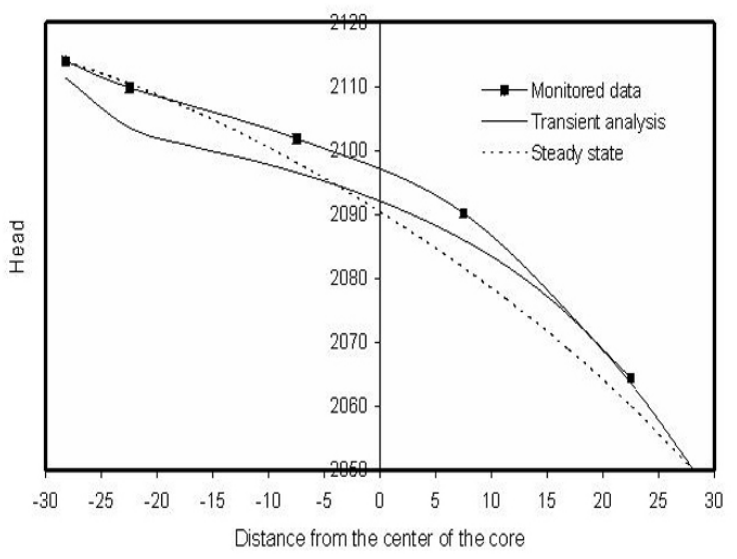

Fig 13: Heads at instant 3 at elevation 2050 (sec. 9) versus horizontal location

It contrasts monitored heads behavior at higher elevations and again, it appears that the high values of construction-induced pore water pressures are responsible for that.Figure 13 shows heads at instant 3. The general trend is similar to higher elevations where the monitored heads are closer to the steady state results at the upstream face of the core and closer to the transient results at the downstream face. However, it appears that the excess constructioninduced pore water pressure in the interior sections of the core have not completely dissipated yet. In general, it was postulated that wide cross section of the dam at elevation $2050 \mathrm{~m}$ restricted the dissipation of high initial pore water pressure induced during the construction.

Conclusions: Pore water pressure heads in Molasadra dam, an earth fill dam with central GC core constructed on Kor River, Iran, was successfully analyzed during 15 months of the first and the second dam impoundments. According to the monitored heads, pressures across the core dropped considerably, reflecting good performance of the core. Steady and transient analyses yielded different results after the impoundments. Monitored heads were closer to the steady state results at the upstream face of the core and closer to the transient results at the downstream face. The fact that pore water pressures at the downstream parts of the core required some time to reach steady state conditions after the first and second impoundments reflects the proper hydraulic behavior of the core. The six month time period between impoundments was long enough for the pore water pressure to reach equilibrium everywhere throughout the core, except where considerable initial construction-induced pore water pressure was observed. High values of constructioninduced pore water pressure at elevation $2050 \mathrm{~m}$ did not dissipate completely during the 6 month period of almost constant reservoir level (el. $2098.3 \mathrm{~m}$ ) and the pore pressures were still at the transient state 
Three dimentional seepage

throughout the core. Furthermore, it was concluded that seepage through the dam was not affected by the hydraulic conductivity function or characteristics of the unsaturated media.

\section{REFERENCES}

Dunnicliff, J and Green, G.E. (1998), Geotechnical instrumentation of monitoring field performance,. John Wiley \& Sons publications, P 531.

Guangxin, Li and Jinhong, Ge, (2003), Free Surface Seepage Analysis Based on the Element-Free Method, Mechanics Research Communications, Vol $30,9-19$.
Jafarzadeh, F. and Shafipour, R. (2003), Three Dimensional Seepage Analysis of Earth Dam Considering Valley Shape Effects, Proceeding of $6^{\text {th }}$ international conference of civil engineering, Isfahan, Iran.

Kutzner, C., (1997), Earth and Rock Fill Dams Principle and Design and Construction, Balkema.

Serafi, J., and Santos, L., (1985), Three Dimensional Seepage Through a Dam Foundation, Proceeding of $14^{\text {th }}$ ICOLD, Lausanne, 767-779

U.S. Army Corps of Engineering,(1995), Instrumentation of Embankment Dams and Levees Engineer Manual, No. EM 1110-2-1908. 